\title{
Suggestion on Reform and Development of the System Organization Mechanism of Science and Technology Association of China from the Perspective of Management
}

\author{
Tingli Pan \\ Chongqing Medical and Pharmaceutical College \\ Chongqing, China 404100 \\ Yuming Xu \\ Chongqing Academy of Social Science \\ Chongqing, China 404100
}

\author{
Zhiguo Yang \\ Chongqing Medical and Pharmaceutical College \\ Chongqing, China 404100 \\ Yanwu Pan \\ Chongqing Technology and Business University \\ Chongqing, China 400067
}

\begin{abstract}
In the critical period of the construction of innovative country and the transformation of government management function, the system of Science and Technology Association should keep up with the needs of times, fulfill the responsibility of times and conduct comprehensive reform and innovation. From the perspective of the present situation and main problems of the reform and development of Science and Technology Association System, this article briefly hackles the basic ideas of the reform and development of Science and Technology Association System. In order to realize the reform and development of Science and Technology Association System, reform can be conducted form three aspects: promoting the operation mechanism of organization of Science and Technology Association, improving the operation mechanism of group member, and optimizing service environment and innovating service mode.
\end{abstract}

Keywords-Science and Technology Association of China; organization system; reform and development

\section{INTRODUCTION}

On March 27, 2016, the general office of the CPC Central Committee issued A Deepening Reform Implementation Plan of Science and Technology Association System, and then provinces and cities made a deepening reform implementation plan of Science and Technology Association System, and put the reform and development of Science and Technology Association System to a new historical stage. This thesis will analyze the facing difficulties and main problems of the reform and development of Science and Technology Association System of China from the perspective of management, and put forward the basic ideas of the reform and development of organization mechanism of Science and Technology Association System, and offer some immature proposals, and give some invaluable contributions to some areas to implement A Deepening Reform Implementation Plan of Science and Technology Association System.

\section{The Present Situation And Main Problems of} REFORM AND DEVELOPMENT OF SCIENCE AND TECHNOLOGY ASSOCIATION SYSTEM

This thesis analyzes the organization mechanism of Science and Technology Association from the perspective of management, and finds some problems existing in the operation system of Science and Technology Association, and the present situation is as follows:

\section{A. The Present Situation of Institutional Framework and Functional Construction}

In 2011, the Eighth National Congress of Science and Technology Association of China examined and agreed to The Regulations of Science and Technology Association of China (Revised Draft), which was submitted by the Seventh Session of National Committee. In these regulations, the nature and function of Science and Technology Association are clearly defined.

The first thing is about the nature orientation of Science and Technology Association. In the regulations of Science and Technology Association, the Article1 is that "Science and Technology Association of China is the mass organization of Chinese scientific and technical works."

Mass organizations refer to each individual in a particular class or group, in order to achieve a common goal or a unilateral goal, through signing some agreements, and they voluntarily form a group or organization. Mass organizations can be divided into spontaneous organizations and government-sponsored organizations. Spontaneous organizations include many social NGOs and academies and seminars etc. There are Labor Union, Women's Federation, 
Communist Youth League, Science and Technology Association, Federation of Philosophy and Social Sciences, Chamber of Commerce and Industry, Charity Society and Overseas Chinese Federation etc. in Government-sponsored organizations.

The second thing is about the function orientation of Science and Technology Association. In the regulations of Science and Technology Association about the orientation, the Article 1 is that "it is the bridge and bound between the party and government to connect with science and technology workers, and the important strength of our country to promote the development of scientific and technical cause." And the Article 2 is that the purpose of Science and Technology Association of China is that "to promote the prosperity and development of science and technology, to improve the popularization and promotion of science and technology, to promote the growth and improvement of scientific and technological personnel, and to improve the combination of science and technology with economy. To reflect the suggestions of scientific and technical workers and safeguard the legitimate rights and interests of scientific and technical workers."

The third thing is about the members of Science and Technology Association. The Article 3 is that "Science and Technology Association of China is composed of National Nature and Science Society, Association, Research Association(the following society, association and academy are shortly named society) and some local Science and Technology Associations."

The fourth thing is about the administration organization of Science and Technology Association. They are Management Function Department of Association and a kind of institution like Science and Technology Service Organization and Service Enterprise in Science and Technology Association. There are three service agencies such as information service center, science and technology activity center and science and technology consulting center and some information transmission medium such as science and technology service webs tires and journals, newspapers. And there are also some enterprise organizations of developing the science and technology resources.

\section{B. Problems in the Organization and Function}

Construction of Science and Technology Association

The Science and Technology Association has evolved into a public service sector in organization mechanism. It represents that it has deviated from the mass organization in the aspect of organization; it has concentrated on the popularization and promotion of science and technology, scientific information push and science and technology information service. And it represents in detail as follows:

1) The management of science and technology association has weakened: First, the development of mass members lags behind. In the process of constructing the management organization of Science and Technology Association, we emphasize the structure and quantity of the individual member and Association members do not cover the scientific and technical workers, so "mass organization" has become a symbol. Therefore, the title assessment of government personnel management department (but the transfer of institutions and research institutes) partly joins in the association organization, and the scientific and technical workers from all social circles are excluded from the system of Science and Technology Association.

Second, Association has a narrow coverage. Association members are mainly from "Academy, Research Association and subordinated organization of Science and Technology Association." On the one hand, with the marketization reform of property right system of scientific and technological institutions, the research association of natural science and the development of the society are becoming weaker, and the society and research association could far from cover the scientific and technical workers; on the other hand, the society and research association are mostly spontaneous mass organization, and its registration is in the Civil Affairs Department and the annual audit is independent from Science and Technology Association, so the relations associated with Association is extremely weak. At the same time, a large number of professional skills workers can not be identified or they can not enter the science and technology workers association after being identified. Such as the original association of engineers and other members of the group, after the reform of state-owned enterprises, they have gradually become shrinked with the reform of evaluation management system of engineers.

Third, the development of regional and industrial associations lags behind. We should gradually cultivate the organization members who regard areas as the unit (such as the Development Zone) and take the vocation as the unit (such as special industry). However, this result still has a large gap with the requirements of the full coverage or the majority of the coverage of the organization.

Fourth, the concept of the member organization system and the association organization system is confused. "Science and Technology Association of China is composed of National Nature and Science Society, Association, Research Association(the following society, association and academy are shortly named society) and some local Science and Technology Associations." And the above regulation needs to be adjusted.

Fifth, personnel training and promotion system is relatively weak. The public welfare personnel training activity of Science and Technology Association system organization is out of touch with the personnel identification mechanism of the labor and personnel department of the government. So there is a problem of defective system and low social identity.

2) The management system of science and technology association is not clear: Science and Technology Association is a mass organization of scientific and technical workers. So it is not an administrative unit or a public institution. But in fact, it is sponsored by the government, according to the civil service regulations, and this mass organization can refer to the civil service law 
management. Therefore, In the process of fulfilling the duty, the tendency of administration becomes more serious, and the members gradually deviate from the duties and functions of the mass organizations.

3) The functions of science and technology association is not clear: The organization function of the system of Science and Technology Association is deviating from the original function to the institutional function of association origanization, and it lacks the organization and command to exert function of member and the organization content tends to the popularization of science. In the aspect of functional construction, such as promoting the prosperity and development of science and technology, and promoting the combination of science and technology with economy, there is a gap between the construction of Science and Technology Association function and the construction of the government think tank and the innovation system of social and economic development.

First, Science and Technology Association is the government public service organization. It does some fulltime jobs, such as the organization and arrangement of science and technology popularization activities, science and technology information push, and science and technology consultation. Among them science and technology information push and popularization activities are the focuses of the work.

Second, the management functions of scientific and technological workers are not available. Government Labor and Personnel Department identify those scientific and technological workers who come from the scientific research institutes of Colleges and universities, manage their files and support some relevant welfare policies. However, they identify or do not decide the professional skill workers. Science and Technology Association does not share the files with Labor and Personnel Management Department, not has the identification function, which results in this fact that the scope of scientific and technological workers of Science and Technology Association is seriously inconsistent with the actual situation.

Third, it is insufficient for Science and Technology Association in the three aspects: the communication and connection with the government function department; using the relevant government departments to establish innovation platform, innovation policy; creating an innovative environment for scientific and technological workers (individual members and group members).

Fourth, the organization promoting function of scientific and technological workers of Science and Technology Association Organization is insufficiency to exert. And they are presented in the following aspects: connecting industry and innovating cross-border integration, participating in regional and industrial technology innovation, promoting economic and social development.

Fifth, the function of jointing innovation and participating in government decision-making of scientific and technological workers of Science and Technology Association Organization needs to be strengthened.

\section{THE BASIC IDEAS OF REFORM AND DEVELOPMENT OF THE SYSTEM OF SCIENCE AND TECHNOLOGY ASSOCIATION}

In the critical period of the construction of innovative country and the transformation of government management function, the system of Science and Technology Association should keep up with the needs of the times, fulfill the responsibility of the times, reform and innovate itself comprehensively. We should comprehensively select and analyze the reform and development plan from the four aspects: promote the prosperity and development of science and technology, promote the popularization and promotion of science and technology, promote the growth and improvement of scientific and technological personnel, and promote the combination of science and technology with economy. The basic ideas are as follows:

The first step is to establish the strategic decision of making a comprehensive transition to nonprofit association organizations form a compound organization mechanism, which is composed of government public service organization of Science and Technology Association and association of scientific and technical workers. Without changing the organization system of the existing governmental agencies in Science and Technology Association, we should gradually transform the public service function into the purchasing public service project of Science and Technology Association, and implement some activities under the financial budget management, such as science and technology popularization and extension activities, science and technology information push, science and technology consulting procurement services and government science and technology innovation service system construction, operation of procurement or sharing. The autonomous management and services of Science and Technology Association includes the development of membership, membership service, creating internal members of collaborative innovation mechanism, innovating the service mechanism of the members to the society, innovating the communication mechanism between the association and the government, and promoting the cooperative ability of the association and the regional innovation and development, expanding the innovation resources allocation services of Science and Technology Association toward scientific and technical workers, making a real practice with the purpose of association in "to promote the prosperity and development of science and technology, to improve the popularization and promotion of science and technology, to promote the growth and improvement of scientific and technological personnel, and to improve the combination of science and technology with economy. To reflect the suggestions of scientific and technical workers and safeguard the legitimate rights and interests of scientific and technical workers." 
IV. THE SUGGESTIONS ON THE REFORM AND DEVELOPMENT OF SYSTEM ORGANIZATION MECHANISM OF SCIENCE AND TECHNOLOGY ASSOCIATION

According to the basic ideas of reform and development of the system organization mechanism of Science and Technology Association, we should comprehensively organize the reform and development, and do perfectly the top-level design, draw up the management outline and make the following specific recommendations.

\section{A. Development of Members}

According to the basic objective of uniting, mobilizing and organizing the whole social scientific and technical workers, we should positively carry out the member organization work.

1) Integrated development of group members: According to the basic ideas of organizing grid, professional organization group members, we should comprehensively organize the group members.

First, we should organize the group members of industry association in a comprehensive way. According to the needs of the development of national strategic emerging industries and social management to enhance the needs of all aspects of construction, we should comprehensively organize the group member and strengthen the organization cohesion and synergy competency of scientific and technical workers in the orientation of development and application of scientific and technological achievements in the area of economy and society.

Second, we should carry out the work in the area of various industrial parks, development zones, and members of major corporate groups throughout the year. And we should strengthen the organization cohesion and synergy competency of scientific and technical workers in the orientation of development and application of scientific and technological achievements in each professional park.

Third, we should further develop and expand the original institute, meanwhile, we could positively promote the construction project of seminar and society. On the one hand, we could strengthen the organization and management work of the association and research institute with the help of civil affairs department; on the other hand, we could create all kinds of conditions to promote the academic exchanges activities in each seminar.

Fourth, keeping pace with the times, we should organize a group member in Guest House on the creative platform.

2) Integrated development of individual members: First, a comprehensive carding of the leading talents in various academic professions shall be conducted for each industry. Meanwhile, it shall be strengthen that the leading role that the leading talents play in industries, major industries and industrial bases.

Second, except the labor personnel management system of government, it shall implement the connection of the Association and group member to promote the evaluation and co-management of various industries, development zones, major enterprises, scientific and technological workers and skilled personnel, and form the coordination mechanism of labor and personnel departments of government.

\section{B. Reform the Organization Mechanism of Science and Technology Association}

1) Further clarify the organizational system of threelevel management of Science and Technology Association: The organizational system of three-level management mainly includes the state, province (municipality directly under the central government, autonomous region), county (District)

2) Adjust the organizational construction in accordance with implementation plan of deepening the reform of system of science and technology program: It is the key to promote the leading talents and representatives of group member scientific and technological workers to work in the organizational construction of the Association.

3) Science and Technology Association shall develop and construct the rational organization system in accordance with the types such as public welfare, non-profit social organization and enterprise: First, in the procurement of government service, on the one hand, it shall be ensured on the basis of rational cost and price level of cost; on the another hand, what shall be pushed to the public as public welfare include popularization of science, science and technology information and science and technology consulting services.

Second, Science and Technology Association shall organize the activities of group members and individual members without profit.

Third, the Association shall develop a variety of science and technology services products to push to the members' community and social for profit.

4) Establish management and organization system of special committee of Science and Technology Association: In order to ensure the professional requirements of association management, the management system of special committee of Science and Technology Association shall be set up, so as to make sure the professional connection and service for the members.

\section{Establish the Rational Operation Mechanism of Science and Technology Association system}

It includes the operation mechanism of the Association and the member system.

1) Improve the operation mechanism of Science and Technology Association

a) Purchasing public service: First, the Association shall convert the original role as science and technology service. Following existing service content, the government shall conduct the financial budget and procurement, and the Association shall implement it. The Association will 
become the third party service carrier of government public service.

Second, the Association shall expand service content of government procurement. According to the requirements of government's public functions transformation, group members of the Association and the development capacity of full coverage of individual members, the Association expands the operating participation of the industry engineering center, industry innovation center, each major innovation center, incubation platform and major scientific and technological platforms. On one hand, what shall be established is the communication and contact between the Association and government departments to reduce the distance from the members to government scientific and technological innovation resources and service resources as soon as possible? At the same time, the several services shall be procured step by step to achieve a number of service resources in management department of science and technology transform to the system of Science and Technology Association and promote the construction of "Small government, big society".

b) Improve member service of the association: First, the Association shall build the member dues management system to ensure that the basic costs and public expenditure of the Association's autonomy management.

Second, the Association shall build the annual general meeting system for the Association's members.

Third, the Association shall establish the management system of transformation plan of development science and technology innovation and growth plan of internal individual of group members.

Fifth, the Association shall establish the member service mechanism of the Association chain or procurement of government public services (especially the major scientific and technological resources, the allocation of science and technology programs and services).

Sixth, the Association shall expand the collaborative innovation between group member and members. In the strategic era of "Internet+", each "Internet+" is a huge and complex system engineering, which needs a high degree of organization and coordination capacity. From the aspect of organization, "Internet+" strategy is taking advantage of the information and technology platform of Internet and the integration of industrial elements, so as to establish contractual coordination organized by the whole industry which has a major position in the Association.

c) Expand the communication and contact between the association and government: First, the Association shall expand the communication and contact between the Association and related government department (Technology management department, Labor and personnel management department), and support the transformation plan of development science and technology innovation of group members and implementation of group member's growth plan.
Second, the Association shall set up the idea bank to ensure that the collaborative innovation's ideas and achievements of the Association members can communicate with the government in time.

d) Improve innovation service ability: The Association shall build service institution and set up Enterprise innovation service center, National "Double Innovation" service center, rural technical service center, Innovation strategy institute, International science and technology exchange center, Training and talent service center, etc.

2) Improve the operation mechanism of group members

First, the Association shall enlarge the coverage range, implement the group member system to bring out the grid organization model of members and strengthen the organization of scientific and technical workers.

Second, the Association shall improve the organizational management mechanism of group members. It shall also practice content requirements "III. Governance Structure and Approach of Comprehensive Reform Society" on Implementation Plan of Deepening the Reform of System of Science and Technology Program in an all-round way.

Third, the Association shall improve the operation mechanism and supervision system. It will ensure to govern group members according to law.

3) Optimize service environment, innovate service mode

First, the Association shall innovative the means of service. It is the key to establish the exchange platform of network information with the means of "Network + Information management", so as to promote fast and efficient communication in the Association, between the S\&T workers, also the Association and its external and guarantee the requirements of reform and development management of the Association.

Second, the Association shall create innovative environment. It includes: setting up academic journals, organizing academic conferences, building information release platform of academic achievement, establishing the evaluation mechanism of academic achievement value, optimizing the academic environment, reversing the unhealthy trend of academic field and establishing a benign growth mechanism of scientific and technological talents.

Third, the Association shall innovative the method of popularization of science. It includes: Establishing the shared modern popularization of science; pushing technology products or technical information to the public in real time on the basis of "Internet+", taping the public demand of science and technology products or technology consumption, in order to realize popularization of science and transform the passive consumption to active consumption.

Forth, the Association shall organize the cooperation for innovation. It includes: organizing innovation strategy research platform; establishing several "Internet Plus" platforms, cracking the language code carrying industry economic management technology of internet information technology platform, establishing a survival mechanism of 
platform, opening up the business model superimposed into the Internet platform of elements of industrial economic system, and establishing ecological environment with the vertical closed loop and high-efficiency operation, not only to stimulate the market demand for scientific and technological innovation and establish a complete and effective total creative space.

Fifth, the Association shall innovative the operation mechanism of think tank and improve the ability of decision and consulting. It shall establish management and operation mechanism of idea bank of the Association, gather the collective wisdom of the majority of scientific and technological workers, and promote the comprehensive improvement of social transformation ability of scientific and technological innovation with collaborative innovation of economic and social management technology and major science and technology.

Sixth, the Association shall collaboratively innovative the management and operation mechanism of society in order to pull the overall development of the national economy. Collaborative innovation is the key which can realize the "Internet+" operating system of industry management and social management, the full integration of Internet technology and modern economic management technology and management objectives of China industrial intelligence. It also can help to pull the comprehensive operation of scientific and technological innovation mechanism to achieve the supply side reform, upgrading of the industrial structure and other strategic demands.

\section{CONCLUSION}

In "Three Technology Conferences" (including National Science and Technology Innovation Conference, Academicians Conference and the Ninth National Congress of China Association of Science and Technology), a series of new requirements were put forward to further strengthen and improve the work of the Association. The reform and development of the Association coincides with a new opportunity, and we should constantly create a new dimension in the work of the Association to contribute to the construction of a socialist scientific and technological group with Chinese characteristics.

\section{REFERENCES}

[1] Yan Dong. Analysis on the Role of Science and Technology Association in Social Management Innovation [D] Shandong: Shandong University, May 2012.

[2] Hu Xiangming. Thinking of Reform and Innovation of System and Mechanism of Science and Technology Association [J]. Science and Technology Forum, February 2014.

[3] Zheng Desheng. Analysis on Hub Type Construction of Association of Science and Technology — the Development Orientation of Association of Science and Technology Based on the Reform of Social Management [J]. Science and Technology Forum, November 2014

[4] Wang Heqing. Chongqing Science and Technology Association: Thinking and Practice on Deepening Reform [J]. Science and Technology Forum, December 2016. 